\title{
Evaluation of the cervical cytology screening programme in an inner city health district
}

\author{
Rosemary Beardow, Juliet Oerton, Christina Victor
}

\begin{abstract}
District health authorities have been instructed to operate a cervical cytology call and recall screening programme using the age-sex registers held by family practitioner committees. A detailed evaluation of implementation in an inner London district showed that 477 out of $687(69 \%)$ invitation letters sent to women by the family practitioner committee were either inaccurate or inappropriate: almost half of the recorded addresses were incorrect and a further fifth of the women were not eligible for a test. Overall, 90 women had a smear, which is only $13 \%$ of the total but $43 \%$ of those found to be eligible. The findings did not differ significantly with age.
\end{abstract}

The findings have major implications not only for the effectiveness of call and recall for screening for cervical cancer but also for the future development of screening for breast cancer in such areas.

\section{Introduction}

Cancer of the cervix accounts for 2000 deaths annually in England and Wales.' Elsewhere well organised regular screening has reduced the number of unnecessary deaths. ${ }^{2-6}$ In contrast, screening programmes in most parts of the United Kingdom have developed unsystematically ${ }^{*}$ and with limited effect. ${ }^{9}$ In an effort to improve organisation and coverage the Department of Health and Social Security instructed all health authorities to introduce a cervical cytology call and recall system based on the computerised age-sex registers held by family practitioner committees by 1 April $1988 .{ }^{10}$

In September 1987 the former Paddington and North Kensington Health Authority (which on 1 April 1988 merged with Brent Health Authority to form Parkside Health Authority) agreed in principle to introduce a cervical screening programme in the district based on the family practitioner committee's register. Concern was expressed, however, about the appropriateness of such a system in an area characterised by high population mobility and social deprivation (Paddington and North Kensington health profile, 1987, unpublished). Results obtained from a scheme run by local general practitioners had initially been disappointing. " Consequently the introduction of call and recall was phased to facilitate the detailed evaluation of implementation and to investigate the nature and extent of any problems encountered.

The first phase of the scheme concerned women registered with six practices ( 12 doctors) in a defined area of north Kensington. Local community staff indicated that, though deprived, the area was not notably different from other parts of the district. The area is, however, served by the Raymede clinic, a large open access family planning and well woman clinic. Computerisation of Kensington and Chelsea and Westminster Family Practitioner Committee was completed in February 1988. The first invitation letters were sent out on 11 April and thereafter on the first of each month. The first phase of the scheme was conducted as though implementation had occurred across the whole district. The evaluation study was conducted for four months to determine the outcome for every woman initially identified for screening by the family practitioner committee's computer.

\section{Methods}

The health authority preserved its policy of three yearly screening for all women aged 20 to 64 .

At monthly intervals the family practitioner committee sent each general practitioner concerned a list of those women on his or her list aged between 20 and 65 with a birthday the next month, assuming a three yearly cycle (therefore one third of women would be called each year). The general practitioners were expected to check this "prior notification list" against the patient's record to determine $(a)$ whether she was still registered with the practice; $(b)$ the date of her last smear; and $(c)$ whether she was still eligible for a smear test. Each general practitioner was requested to amend the list accordingly and return it to the family practitioner committee within four weeks. The family practitioner committee's records were updated from the amended list. Each woman who was still thought eligible for screening was sent a "call" letter inviting her to go to her general practitioner or to the Raymede clinic to have a cervical smear taken. The letter was written as if coming from her general practitioner.

The results of all those cervical smears processed at this hospital were transferred from the laboratory to Kensington and Chelsea and Westminster Family Practitioner Committee for input on to the computer. Thus recall would be initiated at the appropriate time interval.

After 16 weeks a second letter of invitation was sent to apparent non-responders, and if after a further 16 weeks there was still no response the general practitioner was notified accordingly.

A duplicate list of all those women initially identified by the family practitioner committee's computer for screening formed the database for the study. This was amended once the prior notification lists were returned.

Invitation letters returned to the family practitioner committee by the post office as undelivered were collected and noted. The names of all remaining women were checked against the computerised records in the cytology department at this hospital. It was therefore possible to identify $(a)$ women who had had a smear taken within the previous three years and were not currently eligible for a screening test (this not having been indicated by their general practitioners) and $(b)$ women who had responded to the call letter and attended for a smear test. These records related to all
Correspondence to 
smears processed at this hospital, which included all smears taken by the general practitioners taking part in the first phase and at the Raymede clinic (and at any of the health authority's other premises).

Women who had apparently not responded after 12 weeks but who were assumed to have received an invitation letter were sent a short letter and questionnaire designed specifically for the evaluation. This requested the recipient to indicate whether she remembered receiving the original invitation letter, whether she had had a smear taken within the past three years, and why if eligible she had not responded. The envelope containing the letter was clearly marked on the front with a return address if undelivered. A stamped addressed envelope was enclosed.

Four weeks were allowed for the return of the questionnaire. The information was recorded and a further check made of the cytology records in the laboratory. A list was then compiled of those women who had apparently not responded. Attempts were made to interview these women at the addresses recorded to complete the evaluation questionnaire. Initial visits were made on a weekday and subsequent visits on a Sunday over three weeks in November 1988.

\section{Results}

A total of 799 women were identified by the family practitioner committee's computer for cervical screening between April and July 1988. After return of the prior notification lists 687 were apparently still eligible and sent invitation letters. Overall, 90 women responded by attending for a smear test (fig 1 ). Of these, 87 had a negative result, two smears were unsatisfactory, and one showed atypical cells necessitating referral for colposcopy.

Ninety four letters were returned to the family practitioner committee by the post office, which indicated that the addresses given were incomplete, the person concerned no longer lived at the address given, or the building had been demolished. A further 98 women were found not to be eligible for a smear by reference to the cytology computer at this hospital. One person recorded as a woman and sent an invitation was in fact a man (fig 1).

The remaining 404 women were sent the evaluation questionnaire. Seventy five questionnaires were returned undelivered (fig 2). Of the 74 women who completed the questionnaire, 41 considered themselves

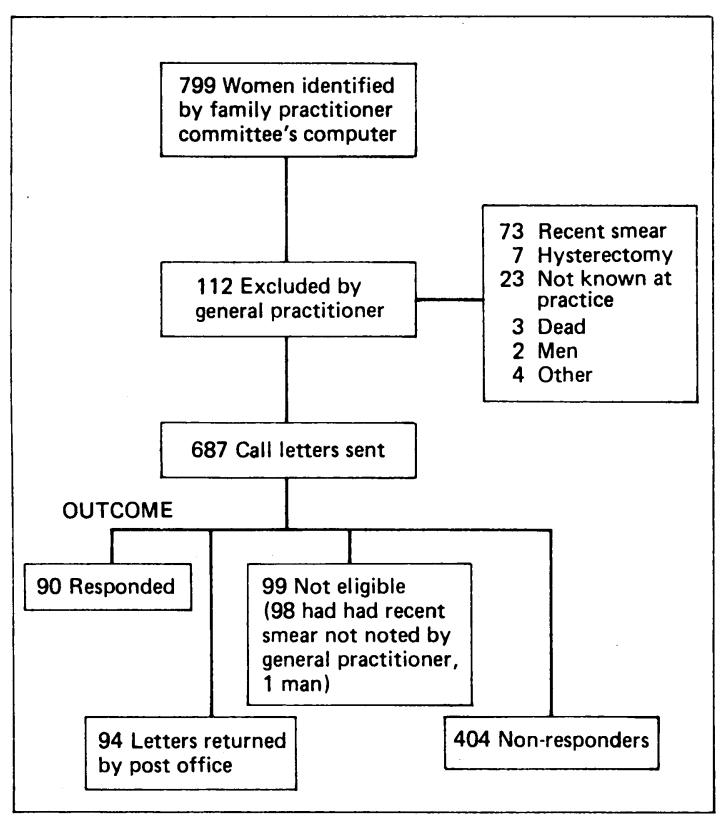

FIG 1-Stage one of evaluation of women eligible for cervical smear ineligible for a smear test, having had a smear within the past three years (32), or having had a hysterectomy (five), or being virgins (four). Thirty three women gave reasons for declining screening, which included fear, lack of time, failure to get around to it, not wanting one, and uncertainty over eligibility.

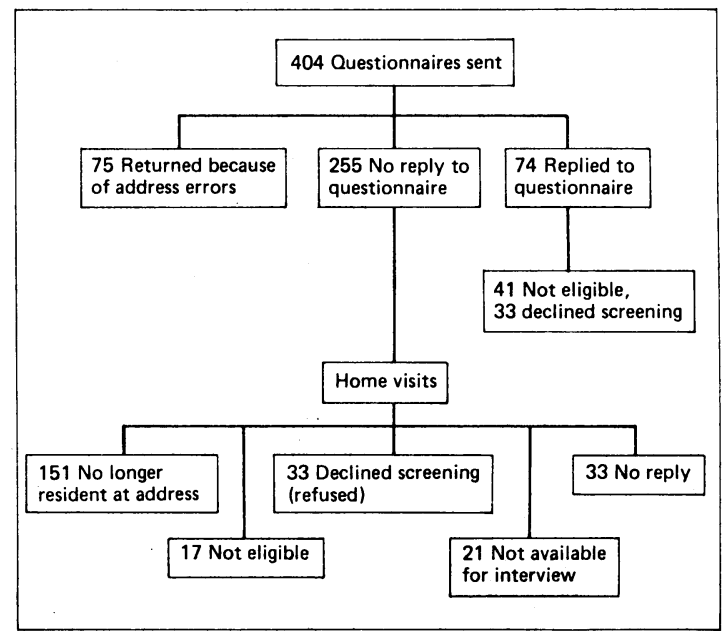

FIG 2-Stage two of evaluation of women eligible for cervical smear. Follow up of non-responders

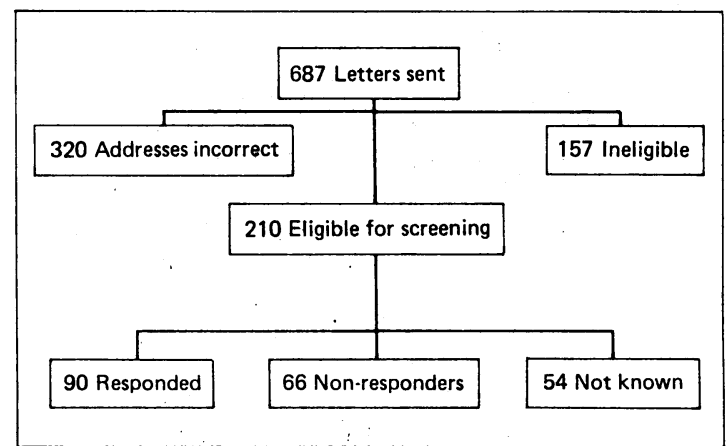

FIG 3-Outcome of family practitioner committee's call invitations

Figure 2 shows that 255 letters elicited no reply. Personal visiting found that 151 of these women definitely no longer lived at the address recorded. Fifty people were interviewed and completed the questionnaire. Reasons given for non-response included ineligibility, having had a recent smear test (11), having had a hysterectomy (two), being men (three), or being a virgin (one). Other reasons included delayed intention to attend (11), not wanting a smear test (six), fear (seven), uncertainty about eligibility (seven), not having time (one), and never having thought about it (one). Of the remaining 54 women, 21 were living at the addresses given but were unavailable for interview while not even this could be established for the remainder.

Figure 3 shows that of the 687 invitation letters sent from the family practitioner committee, 320 went to addresses that were incorrect or no longer applied. A further 157 were sent to women who were not eligible for a smear test. Ninety women had a smear test as a result of receiving the letter.

The proportion of women initially excluded by their general practitioners did not differ significantly with age. For older women, however, exclusion was more likely to have been because of hysterectomy than a recent smear (four out of 11 in those aged 56-65 compared with none of 24 aged 20-29 group). The table presents the outcome for women of different ages. The highest proportion of address errors was found for women aged $32-41(55 \%)$, but there was an error of at least $40 \%$ in all age groups. The table also shows that 
Outcome of family practitioner committee's screening invitation letters by age of women

\begin{tabular}{|c|c|c|c|c|c|}
\hline & \multicolumn{4}{|c|}{$\mathrm{Age}^{\star}$} & \multirow[b]{2}{*}{ Total } \\
\hline & 20-29 & $32-41$ & $44-53$ & 56-66 & \\
\hline Invitation letter sent & 241 & 202 & 134 & 110 & 687 \\
\hline Address incorrect & 104 & 111 & 61 & 44 & 320 \\
\hline Ineligible for smear & 76 & 33 & 28 & 20 & 157 \\
\hline Eligible for smear & 61 & 58 & 45 & 46 & 210 \\
\hline Responder & 27 & 30 & 19 & 14 & 90 \\
\hline True non-responder & 17 & 13 & 18 & 18 & 66 \\
\hline Not known & 17 & 15 & 8 & 14 & 54 \\
\hline
\end{tabular}

^Age range reflects three yearly screening cycle.

the oldest age group responded less well to the invitation letter than the younger women.

\section{Discussion}

All health authorities have been instructed to implement a cervical cytology call and recall system based on the family practitioner committee in an attempt to reduce mortality from cervical cancer. Organisation of such programmes entails the close collaboration and coordination of a variety of services and service providers and considerable time and financial commitment. Integral to the whole process is the computerised age-sex register held by the family practitioner committees. This is, theoretically, the most accurate and extensive population index currently available. Whether this information is of sufficient quality for identification for screening is uncertain. $^{12}$

Our results in Paddington and North Kensington show some fundamental problems, which, though perhaps exacerbated in a deprived inner city area, are of wider importance. About half of all the invitation letters sent out over four months did not reach the women identified because they no longer lived at the addresses recorded on the family practitioner committee's computer. The reasons for problems with addresses relate to the high mobility of the population in the area and the consequent high turnover of patients on general practitioners' lists. Some women fail to register with a general practitioner in their new area of residence while others move locally but fail to inform their general practitioner of their change of address. General practitioners may fail to notify the family practitioner committee of those changes known to them. There was little difference across the different age groups.

A further fifth of the women were sent unnecessary invitation letters as they were not eligible for a test at that time. We could not determine whether this information had been available to the general practitioners concerned and the extent to which failure adequately to complete the prior notification list contributed to the problems encountered. Our experience suggests that practices improved with time, but in even the most assiduous many of the changes of addresses and previous results of smears were not known.

Thus $69 \%$ of the letters sent from the family practitioner committee were either inaccurate or inappropriate. Under normal circumstances most of these women would be recorded as non-responders. This could mean a lot of wasted time and energy for the health authority in attempting to follow them up. It also distorts calculations of uptake rates, which with the increased emphasis on performance measures may adversely affect assessment of the district in comparison with others. For example, the first phase had an apparent uptake rate of only 13\% (90/687).
This, however, rises to $43 \%(90 / 210)$ if the ineligible groups are eliminated. Such calculations are not usually possible, and in normal circumstances 503 women would have been identified at the family practitioner committee as non-responders (this excludes those for whom letters were returned to the family practitioner committee undelivered). In fact, only 66 women were true non-responders.

If the different sources of information are combined (amended prior notification lists, questionnaire, etc) estimating the initial cervical smear state of women in the different age groups is possible. Excluding those with known address errors and those for whom a smear test was not applicable (owing to hysterectomy, being a man, or being a virgin) we found that $60 \%$ (145) of the 20-29 year olds compared with only $29 \%$ (32) of the 56-65 year olds had had a recent smear. Furthermore, the older women responded less well to the invitation to attend for screening: only $30 \%$ (14/46) of eligible women aged 56-65 responded compared with $52 \%$ (30/58) of eligible women aged 32-41. Although the numbers were small, this finding is important as most deaths from cervical cancer still occur in women over 50. Unless uptake is high especially in this age group mortality is unlikely to change.

The accuracy of the family practitioner committee's database is the key to the success of the screening programme. It should improve with time as results are transferred from laboratory to family practitioner committee and from family practitioner committee to family practitioner committee, as general practitioners play a more active part and as those operating the system become more familiar with it. The possible extent of any such improvement cannot, however, be predicted, and we have shown enormous organisational problems in inner London. Even if overcome this may not solve the problem at the heart of the matter-how to get a woman who is not interested to participate in a screening exercise. Both factors become even more acute with the advent of breast cancer screening, which is also based on the family practitioner committee's registers and relates to women between the ages of 50 and 64 .

We thank Ms Sally Jefferies for her help with the interviewing; Ms Roisin Moloney, screening manager, for her help at the family practitioner committee; and Professor Dulcie Coleman and Dr Connie Smith for their support and encouragement.

1 Office of Population Censuses and Survevs. Annual mortality statistics. London: HMSO, 1973-86. (DH2.)

2 Petterson F, Bjorkholm E, Naslund I. Evaluation of screening for cervical cancer in Sweden: trends in incidence and mortality 1958-1980. Int $\mathcal{F}$ Epidemiol 1985;14:521-7.

3 Laara $E$, Day NE, Hakama $M$. Trends in mortality from cervical cancer in the Nordic countries; association with organised screening programmes. Lancet 1987; i:1247-9.

4 Johannesson G, Geirsson G, Day NE. The effect of mass screening in Iceland, 1965-1974, on the incidence and mortality of cervical carcinoma. Int $\mathcal{F}$ Cancer 1978;21:418-25.

5 Anderson GH, Boyes DA, Benedet JL, et al. Organisation and results of the cervical cytology screening programme in British Columbia, 1955-85. Br.Med f 1988;296:975-8.

6 MacGregor JE, Moss SM, Parkin DM, Day NE. A case control study of cervical screening in north-east Scotland. BrMed f 1985;290:1543-6.

7 Imperial Cancer Research Fund. Coordinating Committee on Cervical Imperial Cancer Research Fund. Coordinating Committee on Cervical
Screening. Organisation of a programme for cervical cancer screening. Screening. Organisation of
$B r$ Med $\mathcal{F} 1984 ; 289: 894-5$.

8 Intercollegiate Working Party on Cervical Cytology Screening. Report. London: Royal College of Obstetricians and Gynaecologists, 1987.

9 Roberts A. Cervical cytology in England and Wales 1965-80. Health Trends 1982;14:41-3.

10 Department of Health and Social Security Health Service Management. Cervical screening. London: DHSS, 1988. ( $\mathrm{HC}(87) 1$.)

11 Shroff KJ, Corrigan AM, Bosher M, Edmonds MP, Sacks D, Coleman DV Cervical screening in an inner city area: response to a call system in general practice. Br.Med J 1988;297:1317-8.

12 Bowling A, Jacobson B. Screening: the inadequacy of population registers. BrMed f 1989;298:545-6

(Accepted 18 May 1989) 